\title{
New Shewhart and EWMA Type Control Charts using Exponential Type Estimator with Two Auxiliary Variables under Two Phase Sampling
}

\author{
Syed Muhammad Muslim Raza \\ Department of Quantitative Methods \\ University of Management and Technology, Lahore, Pakistan \\ Department of Mathematics and Statistics \\ Virtual University of Pakistan, Lahore, Pakistan \\ razamuslim4@gmail.com \\ Muhammad Moeen Butt \\ Department of Quantitative Methods \\ University of Management and Technology, Lahore, Pakistan \\ muhammad.moeen@umt.edu.pk
}

\begin{abstract}
In this paper, two new control charts have been proposed, one is shewhart-type and other one is EWMAtype control chart. The proposed control charts are based on the exponential type estimator for mean proposed by Noor-ul-Amin and Hanif (2012). We name them as DS-Shewhart control chart and DSEWMA control chart. The results shows that the DS-Shewhart control chart shows more efficient results to traditional/simple Shewhart and EWMA control charts whereas, the DS-EWMA control chart shows more efficient results to traditional Exponentially Weighted Moving Average (EWMA) and Cumulative Sum (CUSUM) control charts because they uses the information from two phase sampling with two auxiliary variables. The proposed control charts can be used for efficient monitoring of the production process in manufacturing industries. The control limits of the proposed chart are based on estimator, its mean square errors and bias. A simulated example has been used to compare the proposed and traditional/simple EWMA and CUSUM control charts performance based on the average run length-out of control $\left(\mathrm{ARL}_{1}\right)$. It is observed that the proposed chart performs better than existing EWMA and CUSUM control charts. At the end of the paper a real life implementation of the proposed control charts is also provided.
\end{abstract}

Keywords: EWMA, two-phase sampling, two auxiliary variables, Average run length.

\section{Introduction}

Grant \& Leavenworth (1979) describe the "Statistical Process Control (SPC)" as a "useful and important tool used commonly in engineering field to monitor the overall process." SPC can be applied to all kinds of engineering operations. The significant application of the SPC analysis of the process will make the process more consistent and reliable.

Kotz \& Johnson (1988) defined the causes of variations. It can either be due to random (chance) causes and/or assignable causes. Some stable systems of chances are inherent in any particular scheme of production and inspection. But for products to maintain their standards, the assignable causes due to personnel, machines or material must be eliminated or at least reduced. 
Aczel (1989) also stated that the capability of any process is the natural behavior of the particular process after disturbances are eliminated. Montgomery (2007) states that the processes that are operating in the presence of assignable/special causes can be abbreviated as out of control.

Gupta \& Gupta (2009) defined the statistical quality control as one of the most useful and economically important applications of the theory of sampling in the industrial field.

Keller (2015) defined quality control as "Statistical Process Control" which refers to one of a variety of statistical techniques used to develop and maintain a firm ability to produce high quality goods and services.

Statistical Process Control is usually referred as "SPC". It is a method which includes monitoring, controlling and refining of a process. The real life application clearly states that all processes inherent some variation. But sometimes the process shows a great level of discrepancy and results in the occurrence of offensive/unpredictable results. One of the uses of the SPC is to reduce variation to achieve the best objective value.

The Control charts are the most important tool of SPC tool kit. It is commonly used to differentiate between the "assignable and un-assignable causes". The purpose of the effective process monitoring system is to detect the presence of an "assignable cause" as rapidly as possible without stopping checking too often or too late. The control charts are of different types. Some are "memory control charts" and other are "memory-less control charts". Shewhart are memory-less control charts and are being used to detect a large size shift whereas the memory type charts are used for dealing with small size shifts.

The use of statistical quality control charts in different fields of life revealed that the most of the control charts are structured to cater information about the quality characteristic/ studied variable. If we are able to acquire some information about some other variable(s) which is correlated with our variable of interest, we can enhance the efficiency of the control chart by the efficient charting statistic. The additional information is known as auxiliary information and the variable providing the additional information is referred as auxiliary variable. This additional/auxiliary information is used at different points in survey sampling to estimate the unknown parameters. Whenever the auxiliary information is used in the parameter estimation process, the precision of the estimating the parameter is improved. In two-phase sampling/ double sampling our major interest is in estimation of the population mean for the study variable $\mathrm{Y}$ incorporating the additional information from the auxiliary variable(s). The auxiliary variable $\mathrm{X}$ must be correlated with the variable of interest and is included when it can easily be observed. The exponential ratio type estimator is used when the auxiliary variable and the variable of interest is positively or negatively correlated.

\subsection{Some Literature in Relevant Field}

Watson (1937) proposed some estimation procedures using auxiliary information. It was the initial work in the field of auxiliary information. Mandel (1969) gave regression control chart and Zhang (1984 \& 1985) used the additional/auxiliary information in preparation of "cause-selecting-type control chart". Wade and Woodall (1993) proposed 
the prediction limits by inserting some modifications in Zhang (1984) control limits.

Many efficient estimators can be obtained/developed by the use of auxiliary variables, for example, see the researches by Hidiroglou (2001), Kadilar and Cingi(2005), Singh and Vishwakarma (2007), Singh et al. (2008), Hanif et al.(2009), Hamad et al.(2013), Awan and Shabbir (2014).

Riaz (2008) and Riaz and Does (2009) proposed the control chart for the variability using one auxiliary variable for Phase-I. When the additional/auxiliary information is incorporated in the construction of quality control charting attributes, efficiency of such charts is improved. Riaz (2009 \& 2011) suggested control chart for location parameter using one auxiliary variable for Phase I.

Woodall et al (2004) and Rashid et al (2010) proposed control charts using regression estimators' incorporation the use of auxiliary information. Ahmed et al.(2014) also used auxiliary information in designing control charts.

In this study we have used the proposed estimator of mean by Noor-ul-Amin and Hanif (2012) to construct the control chart for two phase sampling using two auxiliary variables.

In the later sections of the paper we have given the expressions for control limits of the proposed Double sampling (DS) Shewhart and Double sampling (DS) EWMA control charts based on an exponential estimator using two auxiliary variables under two phase sampling. An unbiased estimator for Noor-ul-Amin and Hanif (2012) estimator is proposed and its variance has been derived. The proposed estimator and its variance have been used for the construction of control chart limits.

A simulated example has also been included to compare the performance of DS-Shewhart and DS-EWMA control charts with simple Exponentially Weighted Moving Average (EWMA) control chart and Cumulative-sum CUSUM) control chart. The performance is measured on average run length-out of control $\left(\mathrm{ARL}_{1}\right)$. The chart showing less $\mathrm{ARL}_{1}$ will be awarded as more efficient chart as it will be more sensitive to the change and it will be detecting it more rapidly than other chart in comparison.

\section{Methodology}

\subsection{Exponential Estimator}

The estimator proposed by Noor-ul-Amin and Hanif (2012) is given in (1):

$$
t_{1}=\bar{y}_{2} \exp \left[\left(\frac{\bar{Z}-\bar{z}_{2}}{\bar{Z}+\bar{z}_{2}}-\frac{\bar{W}-\bar{w}_{1}}{\bar{W}+\bar{w}_{1}}\right)\right]
$$

Whereas:

$$
e_{\bar{y}_{2}}=\frac{\bar{y}-\bar{Y}}{\bar{Y}}, \quad e_{\bar{w}_{1}}=\frac{\bar{w}-\bar{W}}{\bar{W}}
$$


$\mathrm{E}\left(e_{\bar{y}_{2}}\right)=\mathrm{E}\left(e_{\bar{w}_{1}}\right)=\mathrm{E}\left(e_{\bar{z}_{2}}\right)=0, \mathrm{E}\left(e_{\bar{y}_{2}}^{2}\right)=\theta_{2} C_{y}^{2}, \mathrm{E}\left(e_{\bar{w}_{1}}^{2}\right)=\theta_{1} C_{w}^{2}$,

$\mathrm{E}\left(e_{\bar{y}_{2}} e_{\bar{w}_{1}}\right)=\theta_{1} \rho_{w y} C_{w} C_{y}, \mathrm{E}\left(e_{\bar{y}_{2}} e_{\bar{z}_{2}}\right)=\theta_{2} \rho_{y z} C_{z} C_{y}$,

$\theta_{1}=\frac{1}{n_{1}}-\frac{1}{N}, \theta_{2}=\frac{1}{n_{2}}-\frac{1}{N}, C_{y}=\frac{S_{y}}{\bar{Y}}, \rho_{w y}=\frac{S_{w y}}{S_{w} S_{y}}$,

$S_{w}=\sqrt{\frac{\sum(w-\bar{w})^{2}}{n}}, S_{y}=\sqrt{\frac{\sum(y-\bar{y})^{2}}{n}}, S_{x y}=\sqrt{\frac{\sum(w-\bar{w})(y-\bar{y})}{n}}$

The mean square error (MSE) and bias of the estimator (cf. Noor-ul-Amin \& Hanif (2012))is given as (2) and (3):

$\operatorname{MSE}\left(t_{1}\right) \approx \bar{Y}^{2}\left[\theta_{2}\left(C_{y}^{2}+\frac{C_{z}^{2}}{4}-\rho_{y z} C_{z} C_{y}\right)+\theta_{1}\left(\frac{C_{w}^{2}}{4}+\rho_{w y} C_{w} C_{y}-\frac{\rho_{w z} C_{w} C_{z}}{2}\right)\right]$

$\operatorname{Bias}\left(t_{1}\right) \approx \bar{Y}\left[\frac{\theta_{2} C_{z}}{2}\left(\frac{3 C_{z}}{4}-\rho_{y z} C_{y}\right)-\frac{\theta_{1} C_{w}}{2}\left(\frac{C_{w}}{4}+\frac{\rho_{w z} C_{z}}{2}-\rho_{y w} C_{y}\right)\right]$

As we know that the ratio estimators are biased estimator therefore we propose the unbiased estimator as $t_{2}$ :

$\mathrm{t}_{2}=\bar{y}_{2} \exp \left[\left(\frac{\bar{Z}-\bar{z}_{2}}{\bar{Z}+\bar{z}_{2}}-\frac{\bar{W}-\bar{w}_{1}}{\bar{W}+\bar{w}_{1}}\right)\right]-\bar{Y}\left[\frac{\theta_{2} C_{z}}{2}\left(\frac{3 C_{z}}{4}-\rho_{y z} C_{y}\right)-\frac{\theta_{1} C_{w}}{2}\left(\frac{C_{w}}{4}+\frac{\rho_{w z} C_{z}}{2}-\rho_{y w} C_{y}\right)\right]$

The estimator $\mathrm{t}_{2}$ (given as (4)) is an unbiased estimator of population mean so:

$$
\mathrm{E}\left(\mathrm{t}_{2}\right)=\bar{Y}
$$

The variance of $t_{2}$ estimator is given as (5):

$$
\begin{aligned}
\text { Variance }\left(\mathrm{t}_{2}\right)= & \bar{Y}^{2}\left[\theta_{2}\left(C_{y}^{2}+\frac{C_{z}^{2}}{4}-\rho_{y z} C_{z} C_{y}\right)+\theta_{1}\left(\frac{C_{w}^{2}}{4}+\rho_{w y} C_{w} C_{y}-\frac{\rho_{w z} C_{w} C_{z}}{2}\right)\right] \\
& -\bar{Y}^{2}\left[\frac{\theta_{2} C_{z}}{2}\left(\frac{3 C_{z}}{4}-\rho_{y z} C_{y}\right)-\frac{\theta_{1} C_{w}}{2}\left(\frac{C_{w}}{4}+\frac{\rho_{w z} C_{z}}{2}-\rho_{y w} C_{y}\right)\right]^{2}
\end{aligned}
$$

\subsection{The Proposed Double Sampling (DS) Shewhart Control Chart}

In this section we propose a new shewhart type control chart which is based on type the estimator $t_{2}$ defined in section 2.1 (4). We call it as DS-Shewhart control chart as it is based on double sampling and double auxiliary information.

To evaluate the $D S$ Shewhart control chart we need to find the corresponding $U C L$ and $L C L$ of the control chart. The steps to compute control limits are given as under:

i. Take a population of size $\mathrm{N}$.

ii. The population means of the variables $\bar{y}, \bar{w}$ and $\bar{z}$ are $\bar{Y}, \bar{W}$ and $\bar{Z}$ respectively. 
iii. Take a first phase sample of size $n_{1}$. The first phase sample is drawn by simple random sampling (SRS) without replacement and is selected from the population of "N" units.

iv. Compute $\bar{w}_{1}$ which is the sample mean of variable ' $\mathrm{W}$ ' for the first phase sample.

v. Now select the second phase sample is also selected using simple random sampling without replacement of size $n_{2}$ from the first phase sample of size $n_{1}$.

vi. Compute $\bar{y}_{2}, \bar{w}_{2}$ and $\bar{z}_{2}$ which shows the means of variables ' $\mathrm{Y}$ ', ' $\mathrm{W}$ ' and ' $\mathrm{Z}$ ' respectively for the second phase sample.

vii. Calculate the estimator $\mathrm{t}_{2}$

viii. Simulate steps iii-vii 2000 times.

ix. There are two way to find the value of $\mathrm{K}$.

a) The distribution of the estimator is required for the selection of $\mathrm{K}$ (99.73) quantile point of the estimator calculated data. First calculate the values for $\mathrm{t}_{2}$ and then use any distribution fitting software like Vose Model Risk, Easy fit 5.6 or Minitab 16 to get the most closely fitted distribution to the data. Now get the 99.73 quantile point of fitted distribution.

b) If the distribution of $t_{2}$ is unknown still one can estimate the 99.73 quantile point of the estimated data by identifying the point value under which $99.73 \%$ data points falls.

x.Now compute the control limits of DS-Shewhart control chart using (6).

The control limits of DS Shewhart chart based on the proposed estimator is given as (6):

$$
\begin{aligned}
& L C L=E\left(t_{2}\right)-k \sigma_{t_{2}} \\
& C L=E\left(t_{2}\right) \\
& U C L=E\left(t_{2}\right)+k \sigma_{t_{2}}
\end{aligned}
$$

Where $E\left(t_{2}\right)$ is the mean of $\mathrm{t}_{2}, \sigma_{t 2}$ is the variance of $\mathrm{t}_{2}$ and $\mathrm{k}$ is the 99.73 quartile point of the lognormal distribution or in other words the points of distribution beyond which 0.00135 area lies (so $\mathrm{k}=3$ ).

\subsection{The Proposed Double Sampling (DS) EWMA Control Chart}

In this section we propose a new EWMA type control chart which is based on the estimator $t_{2}$ defined in section 2.1 (4). We call it as DS-EWMA control chart as it is based on two phase sampling with two auxiliary variables.

The test statistics of the proposed DS-EWMA control charts is given as:

$$
D S-E W M A_{i}=\gamma t_{2 i}+(1-\gamma)\left(\mathrm{DS}-\mathrm{EWMA}_{i-1}\right)
$$


Where $\gamma$ is the smoothing constant for the proposed statistic and $t_{2 i}$ is the value of statistic $\mathrm{t}_{2}$ for the $\mathrm{i}^{\text {th }}$ sample. $D S-E W M A_{i-1}$ represents the past information. The initial value $D S-E W M A_{0}$ for starting is the mean of $\mathrm{t}_{2}$.

The control limits of DS-EWMA control chart is based on proposed estimator $t_{2}$ and is given in (7):

$$
\begin{aligned}
& L C L=E\left(t_{2}\right)-L_{D S} \sigma_{t_{2}} \sqrt{\frac{\gamma}{2-\gamma}} \\
& C L=E\left(t_{2}\right) \\
& U C L=E\left(t_{2}\right)+L_{D S} \sigma_{t_{2}} \sqrt{\frac{\gamma}{2-\gamma}}
\end{aligned}
$$

Where $E\left(t_{2}\right)$ is the mean of $t_{2}, \sigma_{t 2}$ is the variance of $t_{2}$ estimator, $\gamma$ is the smoothing parameter and $L_{D S}$ determines the width of the control limits for the proposed DSEWMA chart.

To evaluate the DSEWMA control charts we need to find the corresponding $U C L$ and $L C L$ of the control chart. The steps to compute constant control limits are given as under:

i. Take a population of size $\mathrm{N}$.

ii. The population means of the variables $\bar{y}, \bar{w}$ and $\bar{z}$ are $\bar{Y}, \bar{W}$ and $\bar{Z}$ respectively.

iii. Take a first phase sample of size $\mathrm{n}_{1}$. The first phase sample is drawn by simple random sampling (SRS) without replacement and is selected from the population of "N" units.

iv. Compute $\bar{w}_{1}$ which is the sample mean of variable ' $\mathrm{W}$ ' for the first phase sample.

v. Now select the second phase sample is also selected using simple random sampling without replacement of size $n_{2}$ from the first phase sample of size $n_{1}$.

vi. Compute $\bar{y}_{2}, \bar{w}_{2}$ and $\bar{z}_{2}$ which shows the means of variables ' $\mathrm{Y}$ ', 'W' and ' $\mathrm{Z}$ ' respectively for the second phase sample.

vii. Calculate the estimator $\mathrm{t}_{2}$.

viii. Simulate steps iii-vii 2000 times.

ix. There are two way to find the value of $\mathrm{L}_{\mathrm{DS}}$.

c) The distribution of the estimator is required for the selection of $L_{D S}$ (99.73) quantile point of the estimator calculated data. First calculate the values for $t_{2}$ and then use any distribution fitting software like Vose Model Risk, Easy fit 5.6 or Minitab 16 to get the most closely fitted distribution to the data. Now get the 99.73 quantile point of fitted distribution.

d) If the distribution of $t_{2}$ is unknown still one can estimate the 99.73 quantile point of the estimated data by identifying the point value under which $99.73 \%$ data points falls.

x. Now compute the constant control limits of DS-EWMA control chart given in (7). 


\section{Results and Discussion}

\subsection{Illustrative Example}

To study the features of the proposed DS-Shewhart and DS-EWMA control charts, we have simulated the data and applied the proposed control charts. The simulated data consists of variables; Y representing "Average Food Cost (variable of interest)", W showing "Family Size (Auxiliary variable)" and Z showing "Average Income of households" (Auxiliary variable)". The variables $\mathrm{Y}$ is the study variable and $\mathrm{W}, \mathrm{Z}$ are auxiliary variables. The distributions of $\mathrm{Y}, \mathrm{W}$ and $\mathrm{Z}$ variables are approximate as normal distribution and the estimator $\mathrm{t}_{2}$ distribution is approximate as log-normal distribution.

\subsection{Distribution Properties of $t_{2}$ Estimator}

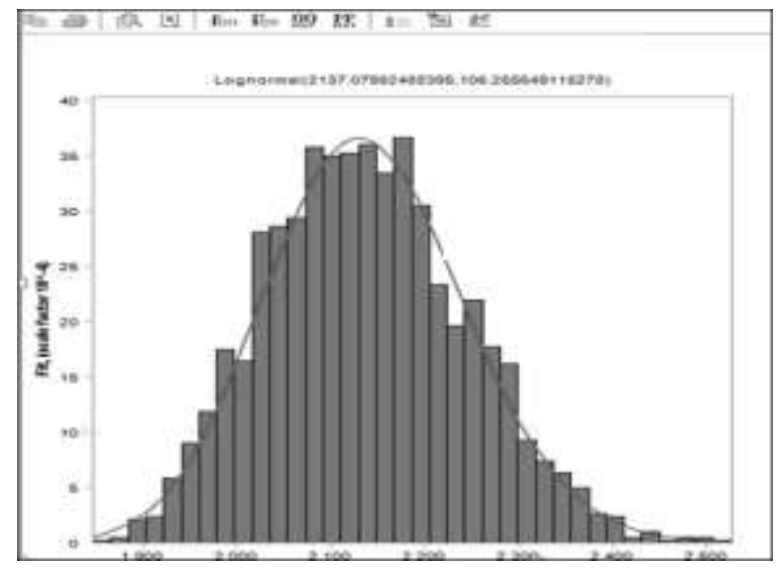

Figure 1: Distribution of $t_{2}$

From figure 1 we can see that the distribution of $t_{2}$ is found to be lognormal distribution with parameters $(2137,106.25)$. Where 2137 is the mean " $\mu$ " and 106.25 is the standard deviation.

\subsection{Goodness of Fit Test}

Table 3.1: Goodness of fit test

\begin{tabular}{|c|c|c|c|c|c|}
\hline \multicolumn{6}{|c|}{ Kalmagorav-smirnav } \\
\hline $\begin{array}{l}\text { Sample size } \\
\text { Statistic } \\
\text { p. Value } \\
\text { pank }\end{array}$ & \multicolumn{5}{|l|}{$\begin{array}{l}2000 \\
0.01976 \\
0.41035 \\
11\end{array}$} \\
\hline$\alpha$ & 0.2 & D.1 & 0.05 & 0.02 & 0.01 \\
\hline Critical Value & 0.02390 & 0.02725 & 0.03037 & 0.03994 & 0,03643 \\
\hline Reject? & No & No & No & No & No \\
\hline \multicolumn{6}{|l|}{ Anderson-Darting } \\
\hline $\begin{array}{l}\text { Sample Size } \\
\text { Stativtic } \\
\text { Rank }\end{array}$ & \multicolumn{5}{|l|}{$\begin{array}{l}2000 \\
0.79563 \\
11\end{array}$} \\
\hline$a$ & 0.2 & 0.1 & o.as & 0.02 & 0.01 \\
\hline Critical Value & 1.3749 & 1.9286 & 2.5018 & 3.2892 & 3.9074 \\
\hline Reject? & No & No & No & No & $\mathrm{Na}$ \\
\hline \multicolumn{6}{|l|}{ Chi-Squared } \\
\hline $\begin{array}{l}\text { Deg. of freedam } \\
\text { Statistic } \\
\text { P.Value } \\
\text { Rank }\end{array}$ & \multicolumn{5}{|l|}{$\begin{array}{l}10 \\
5.3625 \\
0.86569 \\
1\end{array}$} \\
\hline$\alpha$ & 0.2 & 0.1 & 0.05 & 0.02 & 0.01 \\
\hline Critieal value & 13.442 & 15.987 & 18.307 & 21.161 & 23.209 \\
\hline Reject? & No & No & No & No & No \\
\hline
\end{tabular}


The table 3.1 shows the goodness of fit using Kolmogorov-Smirnov, Anderson-Darling and Chi-Squared testing procedures. It shows that the Log normal distribution fits well to the data under study.

Now we take a sample of size $n_{1}=16$ in first phase sample and $n_{2}=9$ units in the second phase sample. It is to be noted that $\mathrm{n}_{1}$ must be greater than $\mathrm{n}_{2}$. In our case, the second phase sample is coming from first phase sample i.e. second phase sample is dependent on first phase sample.

The proposed control charts are applied on the simulated data set to monitor the average cost of food on yearly basis.

\subsection{Numerical Results and Discussion for DS- Shewhart Control Chart}

The control limits are calculated as:

Upper Control Limit: UCL $=2137+3(106)=\mathbf{2 4 5 5}$

Center Line: $\mathrm{CL}=2137$

Lower Control Limit: $\mathbf{L C L}=2137-3(106)=1819$

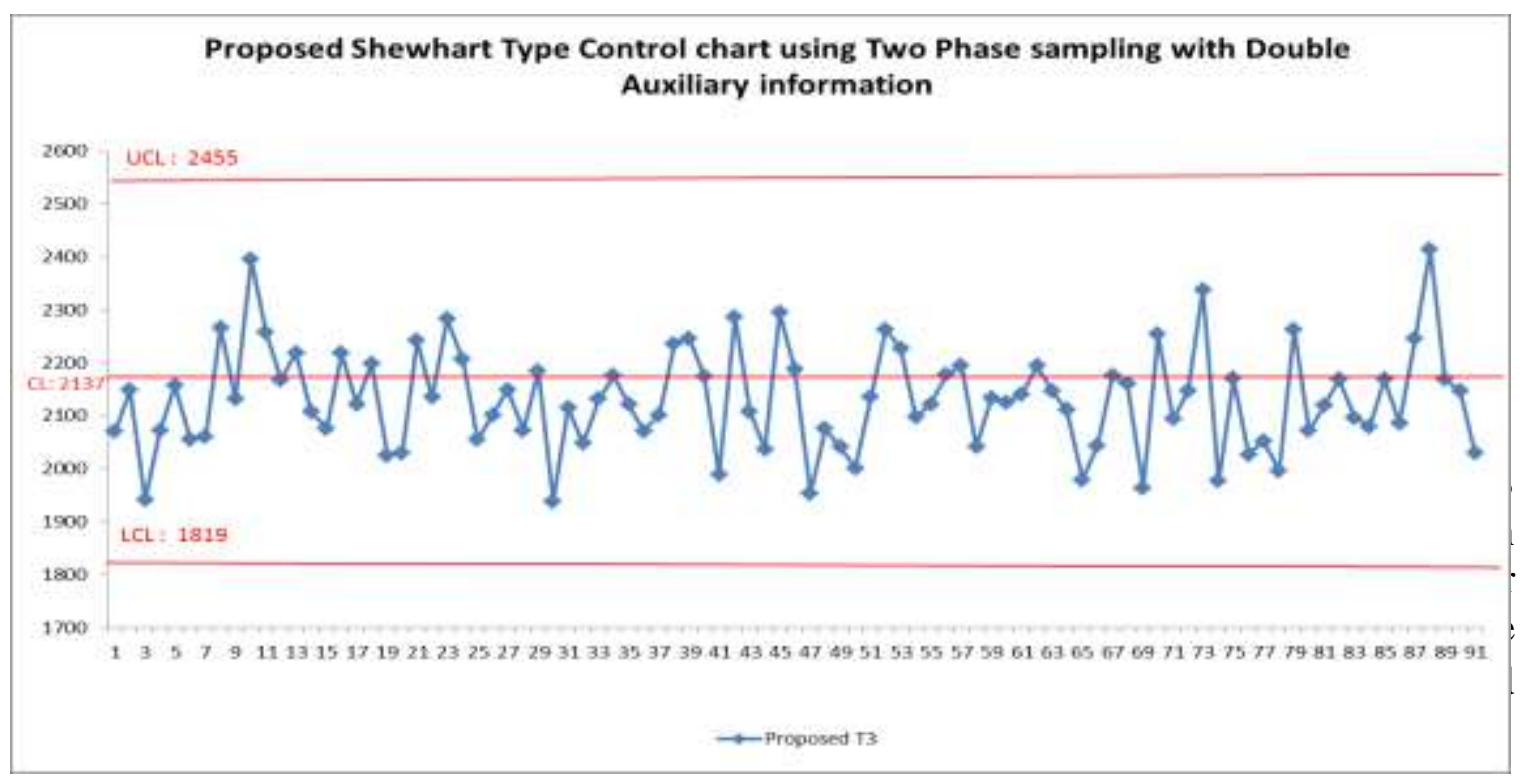

Table 3.2: ARL comparison of Shewhart $\bar{X}$ control chart and DS Shewhart control chart

\begin{tabular}{|c|c|c|c|c|}
\hline \multicolumn{3}{|c|}{ DS Control Chart } & \multicolumn{2}{|c|}{ She whart X-Bar control chart } \\
\hline Shifts & $5 \%$ increase & $10 \%$ increase & $5 \%$ increase & $10 \%$ increase \\
\hline$\mu \rightarrow$ & 2243 & 2350 & 2243 & 2350 \\
\hline$\underset{\vec{z}}{\stackrel{\vec{z}}{z}}$ & 31 & 15 & 102 & 72 \\
\hline
\end{tabular}


From table 3.2 and figure 3.3 we observe that the $\mathrm{ARL}_{1}$ values for DS Shewhart control chart is less than shewhart $\bar{X}$ control chart, which shows DS Shewhart control chart performs better than the shewhart $\bar{X}$ control chart.

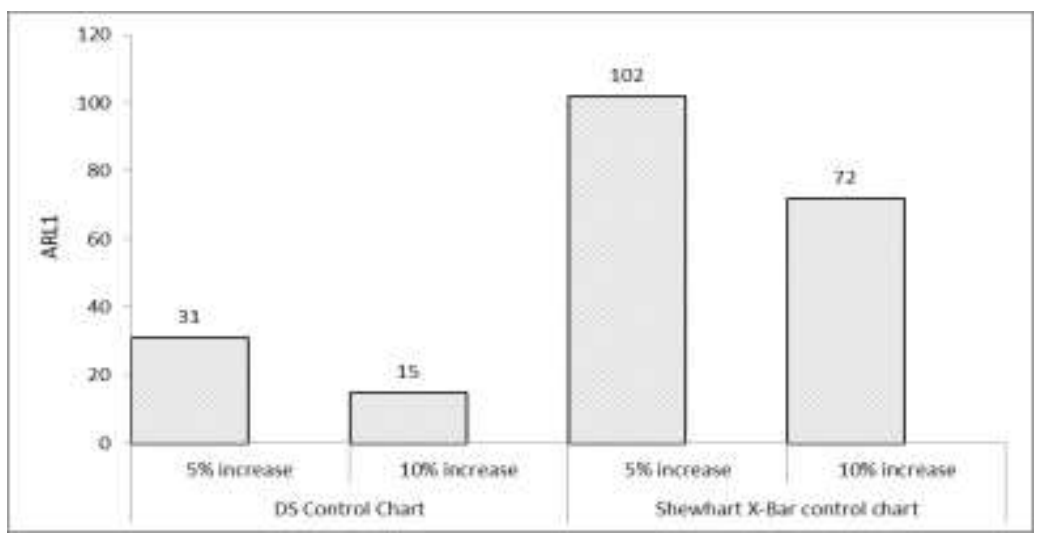

Figure 3: ARL comparison of Shewhart $\bar{X}$ and DS Shewhart control chart

We have also applied exponentially weighted moving average (EWMA) control chart on the samples (from study variable) and found the results given in table 3.3.

Table 3.3: ARL comparison of EWMA control chart and DS Shewhart control chart

\begin{tabular}{|c|c|c|c|c|}
\hline \multicolumn{3}{|c|}{ DS Control Chart } & \multicolumn{2}{|c|}{ EWMA control chart } \\
\hline Shifts & $5 \%$ increase & $10 \%$ increase & $5 \%$ increase & $10 \%$ increase \\
\hline$\mu \rightarrow$ & 2243 & 2350 & 2243 & 2350 \\
\hline$\vec{z}$ & 31 & 15 & 37 & 19 \\
\hline
\end{tabular}

From table 3.3 and figure 3.4 we observe that the $A R L_{1}$ values for DS Shewhart control chart is less than EWMA control chart, which shows DS Shewhart control chart performs better than the EWMA control chart.

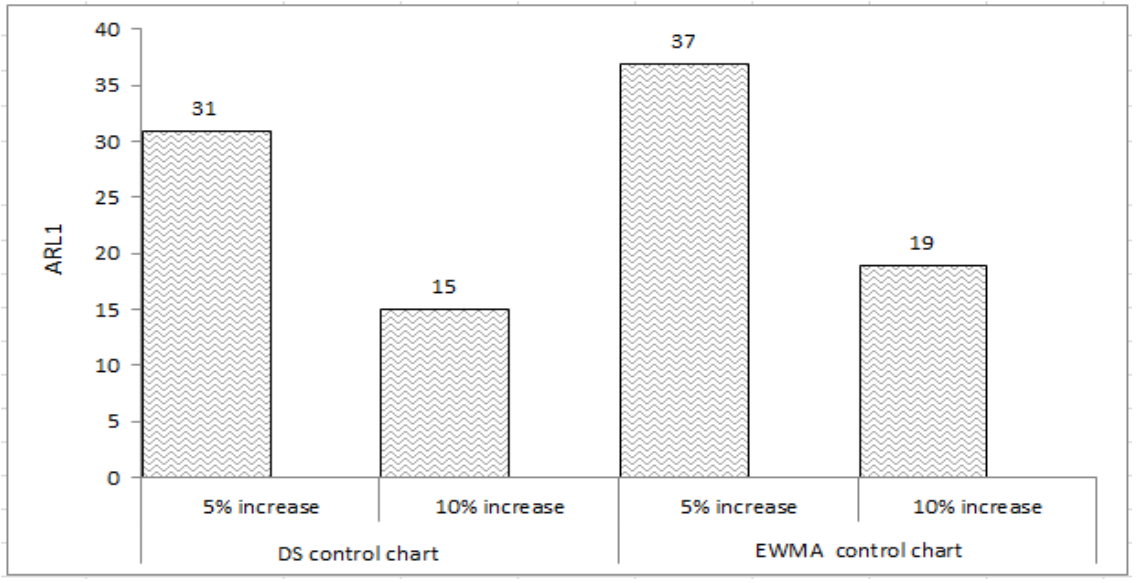

Figure 4: ARL comparison of EWMA and DS Shewhart control charts 
Table 3.4: ARL comparison of EWMA control chart and DS Shewhart control chart for increase in shifts

\begin{tabular}{|c|c|c|}
\hline Shift (\%) & $\begin{array}{c}\text { DS Shewhart } \\
\text { Control charts }\end{array}$ & EWMA control chart \\
\hline $\mathbf{3}$ & 55 & 72 \\
\hline $\mathbf{5}$ & 31 & 37 \\
\hline $\mathbf{8}$ & 25 & 33 \\
\hline $\mathbf{1 0}$ & 15 & 19 \\
\hline $\mathbf{1 3}$ & 10 & 17 \\
\hline $\mathbf{1 5}$ & 7 & 13 \\
\hline $\mathbf{2 0}$ & 4 & 8 \\
\hline
\end{tabular}

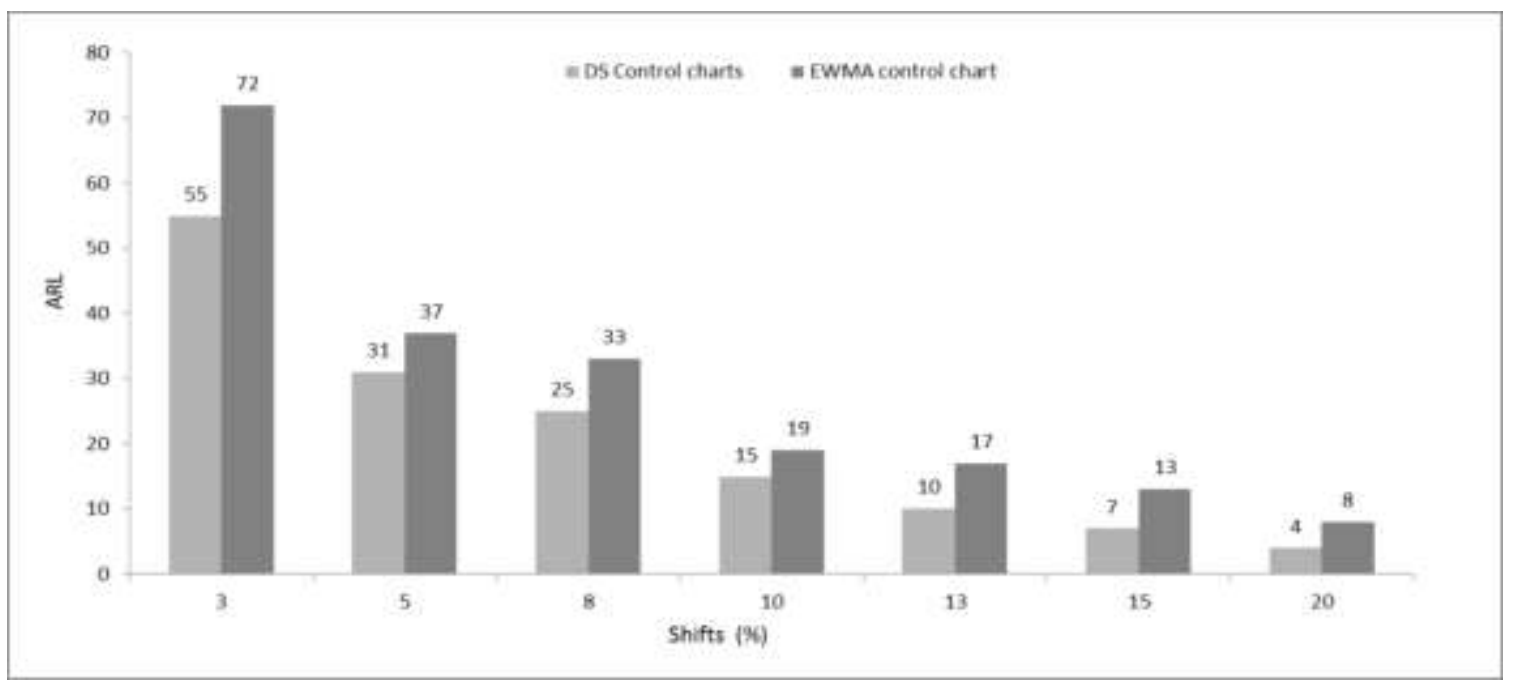

Figure 5: ARL comparison of EWMA and DS Shewhart control charts for increase in shifts

The table 3.4 and figure 3.5 shows that the DS Shewhart control chart performs better than EWMA control chart for increase in shifts in location parameter. DS Shewhart control chart shows less ARL values than EWMA chart which mean DS Shewhart control chart performs better than EWMA control chart. 
Table 3.5: ARL comparison of EWMA control chart and DS Shewhart control chart for decrease in shifts

\begin{tabular}{|c|c|c|}
\hline Shift $(\boldsymbol{\%})$ & $\begin{array}{c}\text { DS Shewhart } \\
\text { Control charts }\end{array}$ & EWMA control chart \\
\hline $\mathbf{3}$ & 45 & 66 \\
\hline $\mathbf{5}$ & 29 & 34 \\
\hline $\mathbf{8}$ & 24 & 30 \\
\hline $\mathbf{1 0}$ & 15 & 18 \\
\hline $\mathbf{1 3}$ & 11 & 15 \\
\hline $\mathbf{1 5}$ & 8 & 10 \\
\hline $\mathbf{2 0}$ & 5 & 7 \\
\hline
\end{tabular}

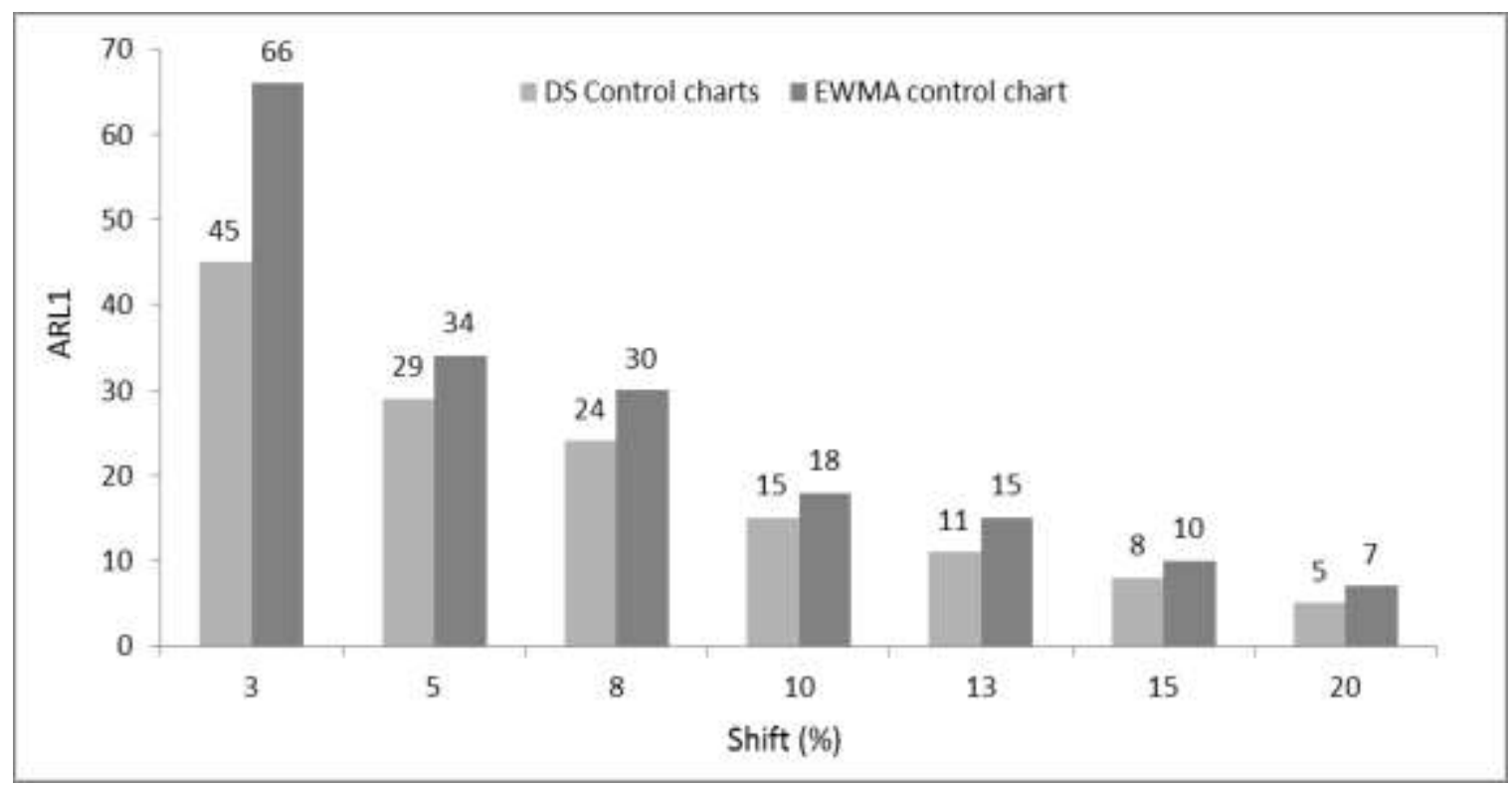

Figure 6: ARL comparison of EWMA and DS-Shewhart control charts for decrease in shifts

The table 3.5 and figure 6 shows that the DS Shewhart control chart performs better than simple EWMA control chart for decrease in shifts in location parameter. DS Shewhart control chart shows less ARL values than EWMA chart which mean DS Shewhart control chart performs better than EWMA control chart. 


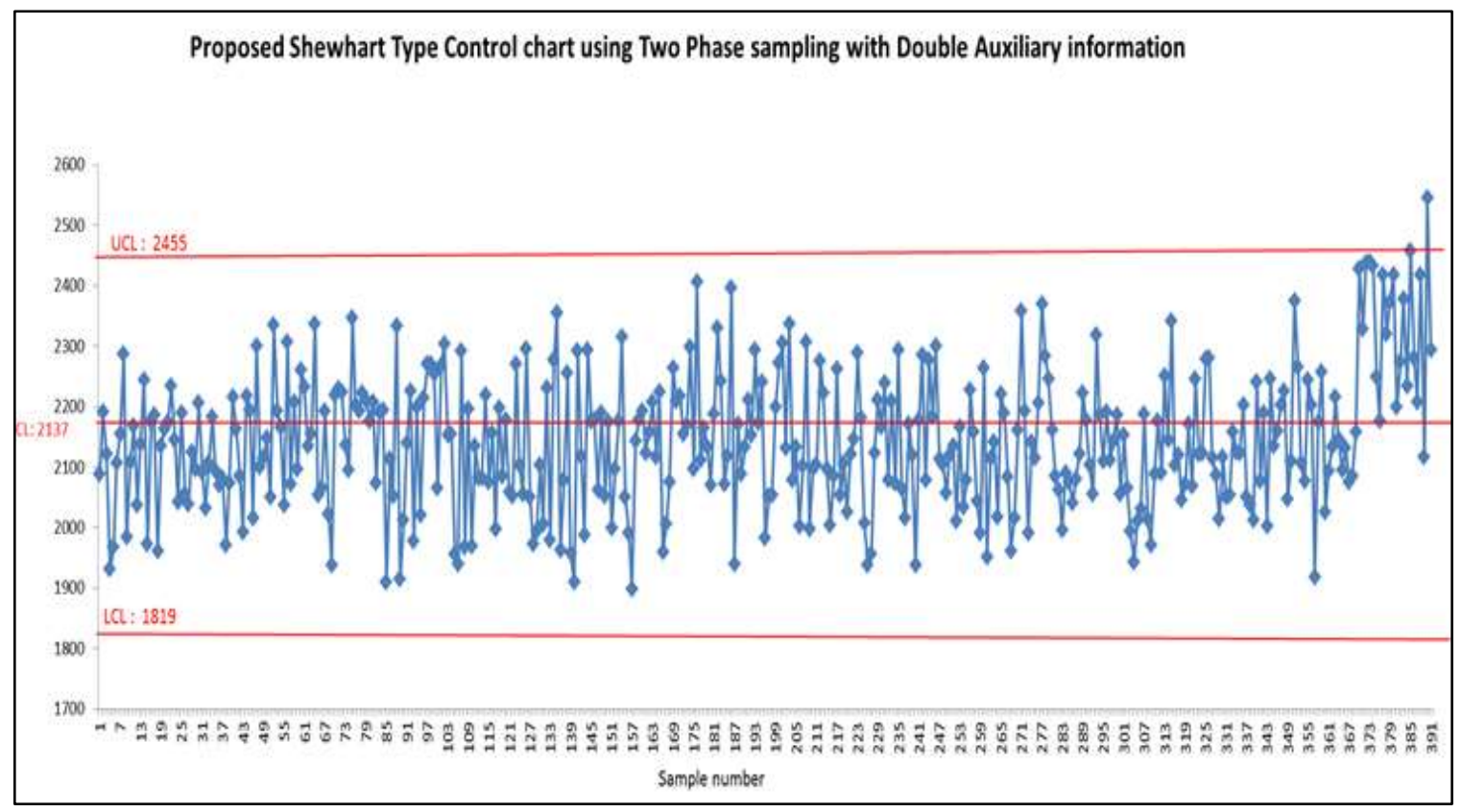

Figure 7: $\mathrm{ARL}_{1}$ for DS Shewhart Control Chart

The figure 7 indicates that when $10 \%$ shift is introduced in mean (location parameter) the DS Shewhart control chart shows out of control at 385 sample number. As the in-control ARL is set at 370 so the $\mathrm{ARL}_{1}$ value is observed as 15 .

\subsection{Numerical Results and Discussion for DS- EWMA Control charts}

The control limits are calculated using $\gamma=0.1, L_{D S}=2.9$ :

Upper Control Limit $=2137+2.9(106)(0.23)=2206$

Center Line $=2137$

Lower Control Limit $=2137-2.9(106)(0.23)=2067$

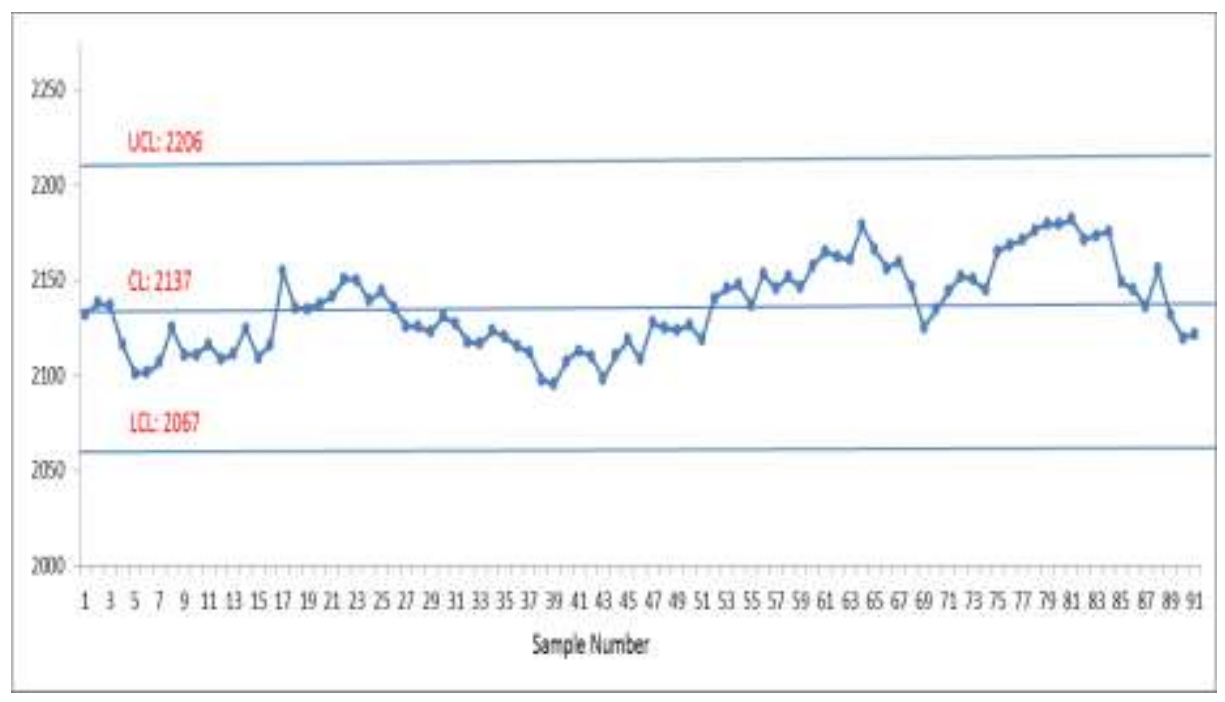

Figure 8: DS-EWMA control chart 
The figure 8 shows the first 91 sample points for the proposed DS-EWMA control chart using two phase sampling with two auxiliary variables where in control average run length $\left(\mathrm{ARL}_{\mathrm{o}}\right)$ is fixed at 370. We introduce the shift after 370 in control points and observe the $\mathrm{ARL}_{1}$ as given in table 6. For comparison purpose we also apply shewhart $\bar{X}$ control chart on sample from variable of interest and found the results given in table 3.6.

Table 3.6: ARL comparison of Shewhart $\bar{X}$ control chart and DS-EWMA control chart

\begin{tabular}{|c|c|c|c|c|}
\hline \multicolumn{2}{|c|}{ DS EWMA Control Chart } & \multicolumn{2}{c|}{ Shewhart X-Bar control chart } \\
\hline Shifts & $\mathbf{5 \%}$ increase & $\mathbf{1 0 \%}$ increase & $\mathbf{5 \%}$ increase & $\mathbf{1 0 \%}$ increase \\
\hline$\square \rightarrow$ & 2243 & 2350 & 2243 & 2350 \\
\hline$\vec{z}$ & 20 & 6 & 102 & 72 \\
\hline
\end{tabular}

From table 3.6 and figure 9 we observe that the $\mathrm{ARL}_{1}$ values for DS EWMA control chart (for 5 and $10 \%$ increase in shift) is less than shewhart $\bar{X}$ control chart, which shows DS EWMA control chart performs better than the shewhart $\bar{X}$ control chart.

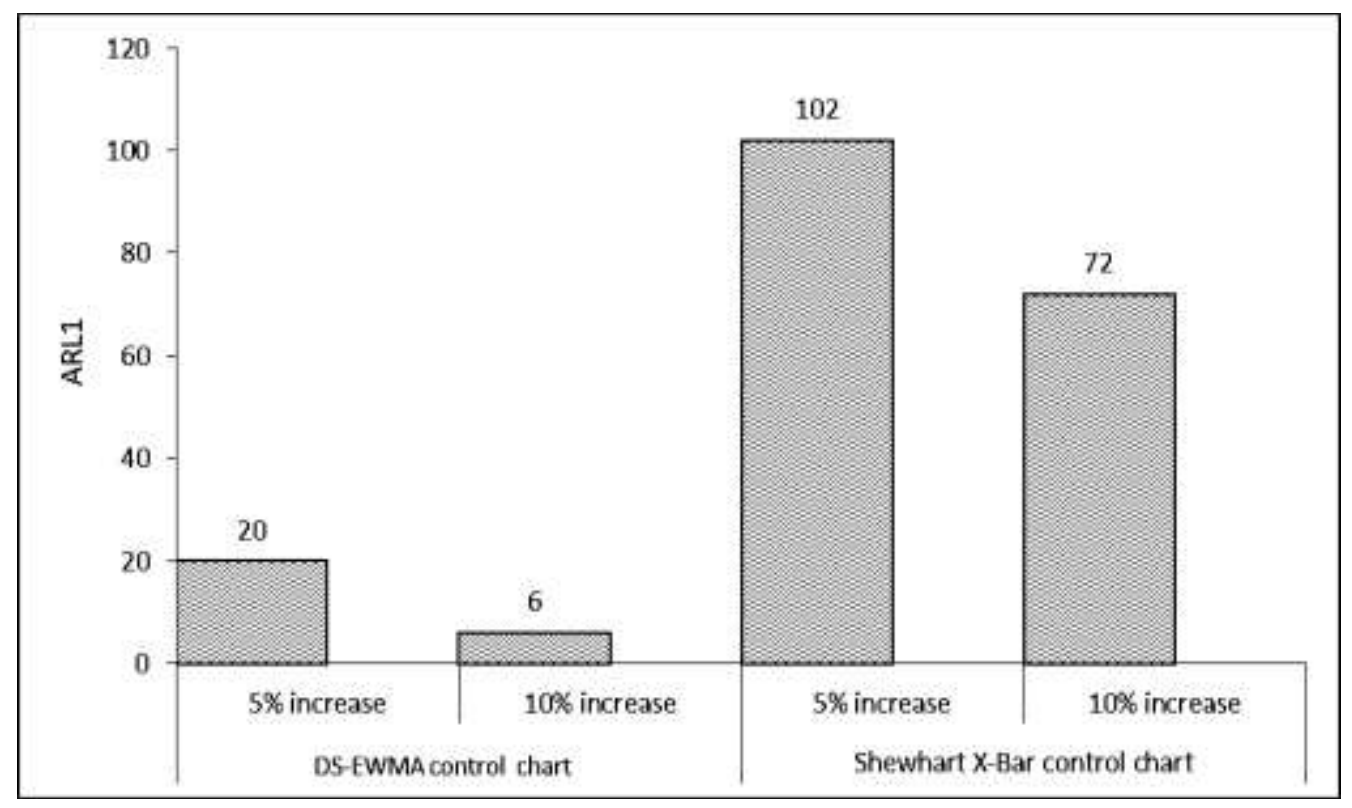

Figure 9: ARL comparison of Shewhart $\bar{X}$ and DS EWMA control chart

The exponentially weighted moving average (EWMA) control chart is also applied on the samples (from study variable) and results are compared with DS- EWMA chart. The results are given in table 7 . 
Table 3.7: ARL comparison of EWMA control chart and DS EWMA control chart

\begin{tabular}{|c|c|c|c|c|}
\hline \multicolumn{3}{|c|}{ DS-EWMA Control Chart } & \multicolumn{2}{c|}{ EWMA control chart } \\
\hline Shifts & $\mathbf{5 \%}$ increase & $\mathbf{1 0 \%}$ increase & $\mathbf{5 \%}$ increase & $\mathbf{1 0 \%}$ increase \\
\hline$\square \rightarrow$ & 2243 & 2350 & 2243 & 2350 \\
\hline$\vec{z}$ & 20 & 6 & 37 & 19 \\
\hline
\end{tabular}

From table 3.7 and figure 10 we observe that the $\mathrm{ARL}_{1}$ values for DS EWMA control chart (for 5 and 10\% increase in shift) is less than EWMA control chart, which shows DS EWMA control chart performs better than the EWMA control chart.

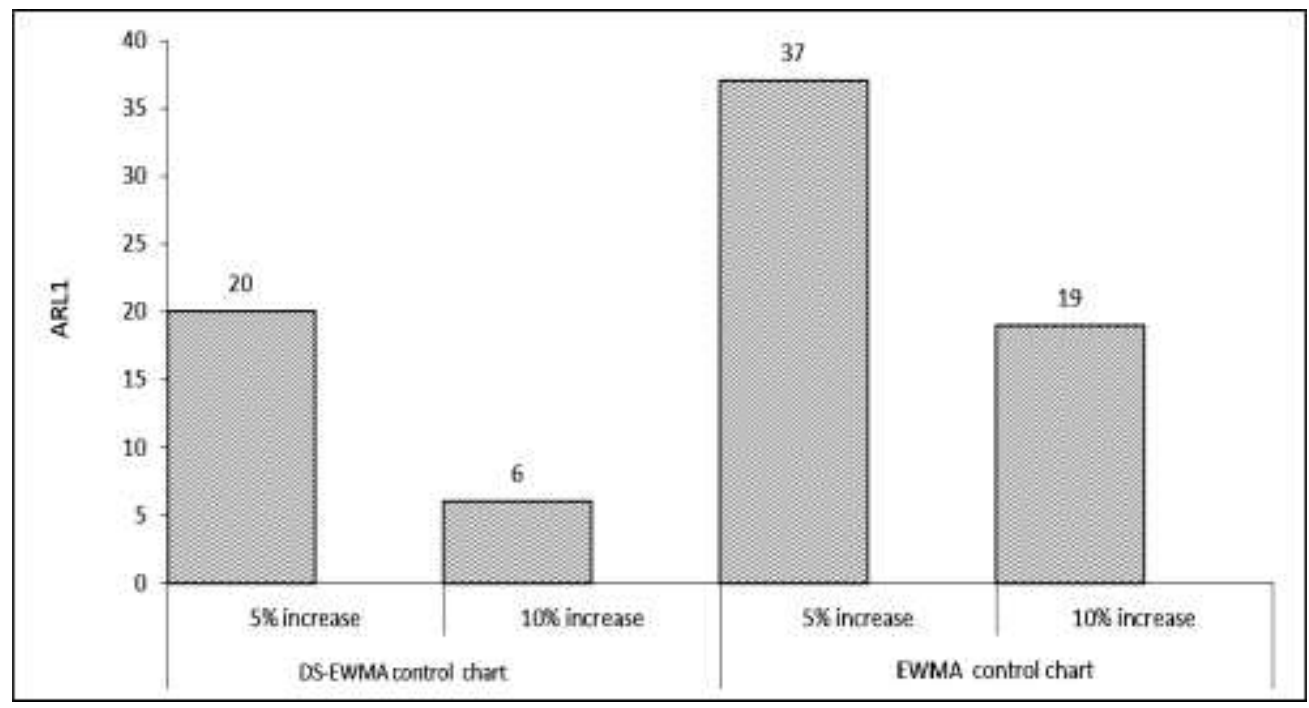

Figure 10: ARL comparison of EWMA and DS-EWMA control charts

Table 3.8: ARL comparison of EWMA control chart and DS-EWMA control chart for increase in shifts

\begin{tabular}{|c|c|c|}
\hline Shift $(\boldsymbol{\%})$ & DS EWMA Control charts & EWMA control chart \\
\hline $\mathbf{3}$ & 35 & 72 \\
\hline $\mathbf{5}$ & 20 & 37 \\
\hline $\mathbf{8}$ & 16 & 33 \\
\hline $\mathbf{1 0}$ & 6 & 19 \\
\hline $\mathbf{1 3}$ & 4 & 17 \\
\hline $\mathbf{1 5}$ & 3 & 13 \\
\hline
\end{tabular}




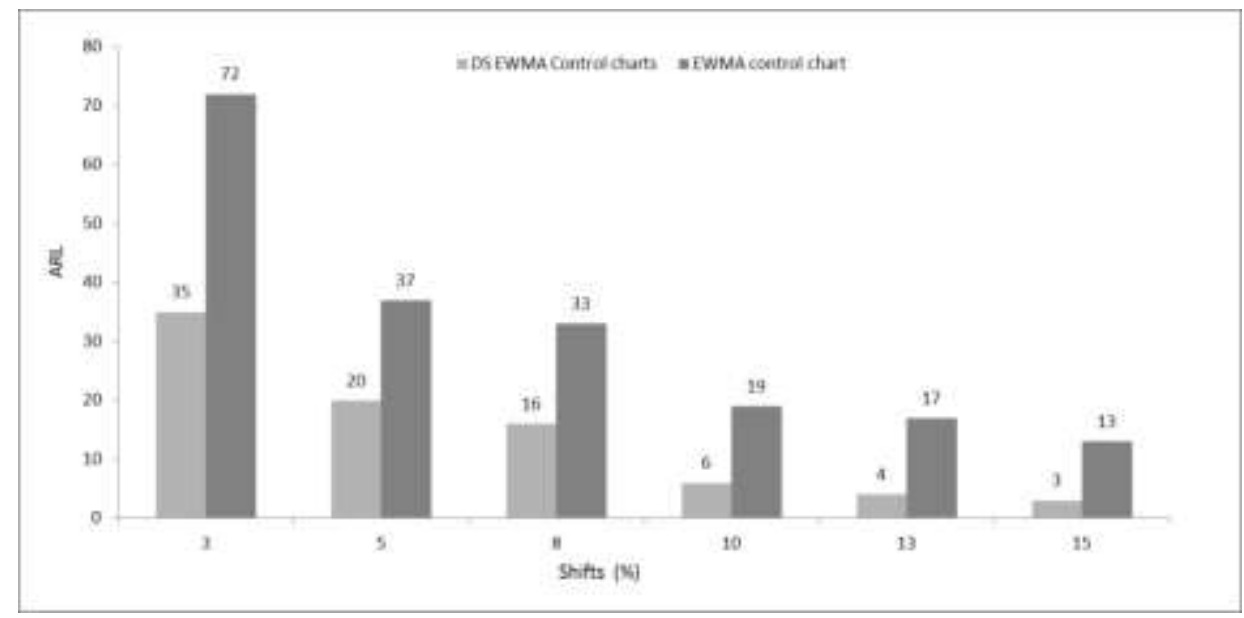

Figure 11: ARL comparison of EWMA and DS-EWMA control charts for increase in shifts

The table 3.8 and figure 11 shows that the DS EWMA control chart performs better than EWMA control chart for increase in shifts. DS-EWMA control chart shows less ARL values than EWMA chart which mean DS EWMA control chart performs better than EWMA control chart. The performance of the control charts enhances with the increase in shift i.e. $3 \%$ to $15 \%$ increase in location parameter.

Table 3.9: ARL comparison of CUSUM control chart and DS-EWMA control chart for increase in shifts

\begin{tabular}{|c|c|c|}
\hline Shift (\%) & DS-EWMA Control charts & CUSUM control chart \\
\hline $\mathbf{3}$ & 35 & 51 \\
\hline $\mathbf{5}$ & 20 & 42 \\
\hline $\mathbf{8}$ & 16 & 28 \\
\hline $\mathbf{1 0}$ & 6 & 17 \\
\hline $\mathbf{1 3}$ & 4 & 12 \\
\hline $\mathbf{1 5}$ & 3 & 9 \\
\hline
\end{tabular}

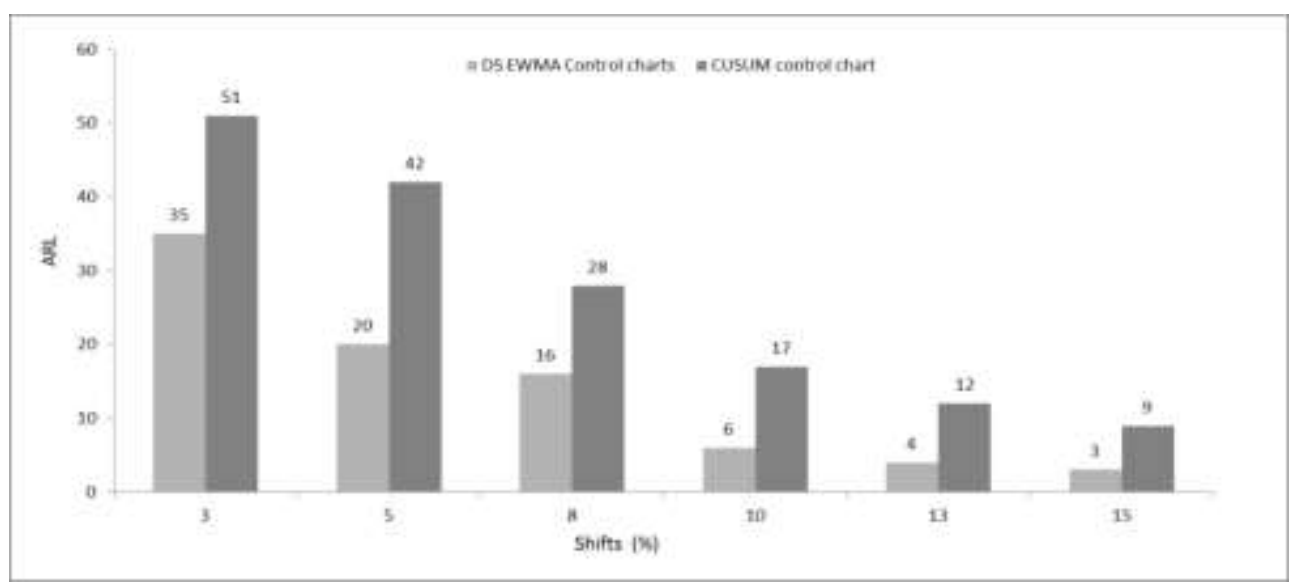

Figure 12: ARL comparison of CUSUM and DS-EWMA control charts for increase in shifts 
The table 3.9 and figure 12 shows that the DS-EWMA control chart performs better than Cumulative sum (CUSUM) control chart for increase in shifts. DS-EWMA control chart shows less ARL values than CUSUM chart which mean DS-EWMA control chart performs better than CUSUM control chart. The performance of the control charts enhances with the increase in shift i.e. $3 \%$ to $15 \%$ increase in location parameter.

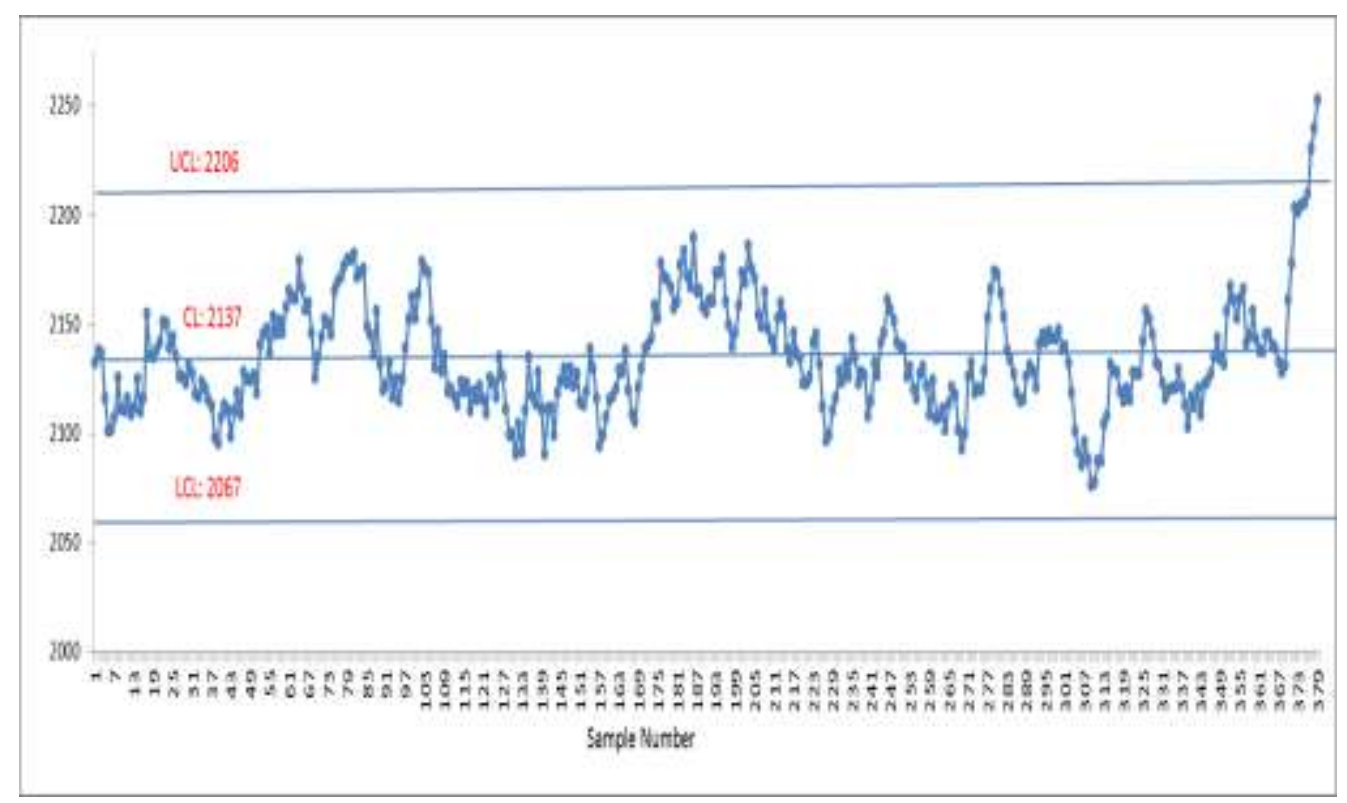

Figure 13: $\mathrm{ARL}_{1}$ for DS- EWMA Control Chart

The figure 13 indicates that when $10 \%$ shift is introduced in mean (location parameter) the DS- EWMA control chart shows out of control at 376 sample number. As the incontrol ARL is set at 370, so the out of control ARL $\left(A R L_{1}\right)$ value is observed as 6.

Table 3.10: ARL comparison of DS-Shewhart control chart and DS-EWMA control chart for increase in shifts

\begin{tabular}{|c|c|c|}
\hline Shift $(\boldsymbol{\%})$ & DS Shewhart Control charts & DS-EWMA Control charts \\
\hline $\mathbf{3}$ & 45 & 35 \\
\hline $\mathbf{5}$ & 29 & 20 \\
\hline $\mathbf{8}$ & 24 & 16 \\
\hline $\mathbf{1 0}$ & 15 & 6 \\
\hline $\mathbf{1 3}$ & 11 & 4 \\
\hline $\mathbf{1 5}$ & 8 & 3 \\
\hline
\end{tabular}




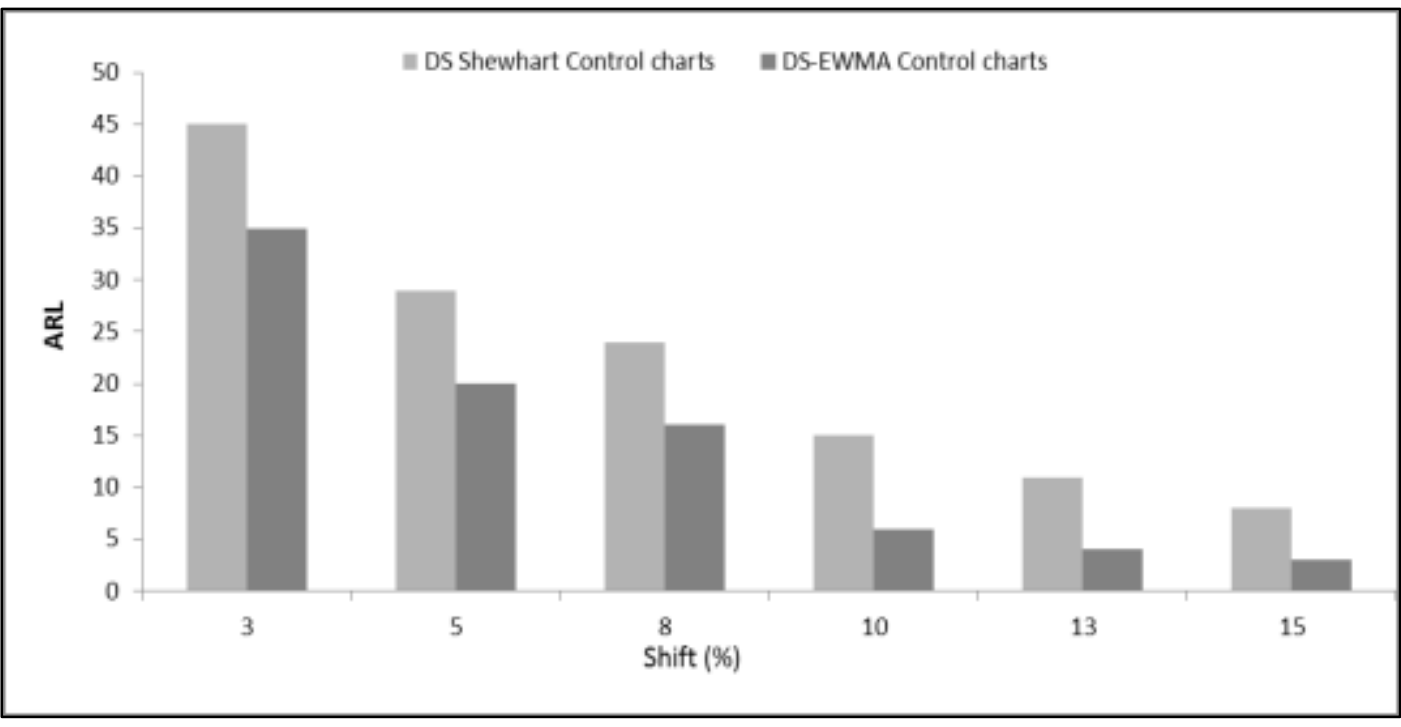

Figure 14: $\mathrm{ARL}_{1}$ Comparison for DS- Shewhart and DS- EWMA Control Charts for increase in shifts

The table 3.10 and figure 14 shows that the DS-EWMA control chart performs better than DS-Shewhart control chart for increase in shifts. DS-EWMA control chart shows less ARL values than DS-Shewhart control chart from 3-15\% increase in location parameter shifts, which mean DS-EWMA control chart performs better than DSShewhart chart. The performance of both control charts enhances with the increase in shift i.e. $3 \%$ to $15 \%$ increase in location parameter.

\section{Application of Proposed Control Charts on Real Data Set}

We have considered the data set based on the non-isothermal continuous stirred tank chemical reactor model (namely CSTR process), which has been widely used as benchmark in fault detection and diagnosis, cf. Ahmed et al. (2014). The CSTR process comprises on nine process variables, among which, we have considered outlet concentration of the product ( $\mathrm{CA}$ in kmole/m3) as $\mathrm{Y}$, Inlet temperature (TO in Kelvin) as $\mathrm{X}$ and Flow rate of reactant $\mathrm{A}$ (FA in $\mathrm{m} 3 / \mathrm{min}$ ) as $\mathrm{Z}$ for our example. We have used the first 200 values of the data set for our application purpose.

\subsection{DS-Shewhart Control Chart}

The procedure defined in section 2.2 is used to evaluate the DS-Shewhart control chart on the real data set of CSTR process (defined above). The distribution of the estimator is found as log-normal with parameters $(0.7945,0.0135)$. The control limits of DS Shewhart chart based on the proposed estimator is given as:

$$
\begin{aligned}
& L C L=E\left(t_{2}\right)-k \sigma_{t_{2}}=0.7945-3(0.0135)=0.75394 \\
& C L=E\left(t_{2}\right)=0.7945 \\
& U C L=E\left(t_{2}\right)+k \sigma_{t_{2}}=0.7945+3(0.0135)=0.834996
\end{aligned}
$$


Where $E\left(t_{2}\right)$ is the mean of $\mathrm{t}_{2}, \sigma_{t 2}$ is the variance of $\mathrm{t}_{2}$ and $\mathrm{k}$ is the 99.73 quartile point of the lognormal distribution or in other words the points of distribution beyond which 0.00135 area lies (so $\mathrm{k}=3$ ).

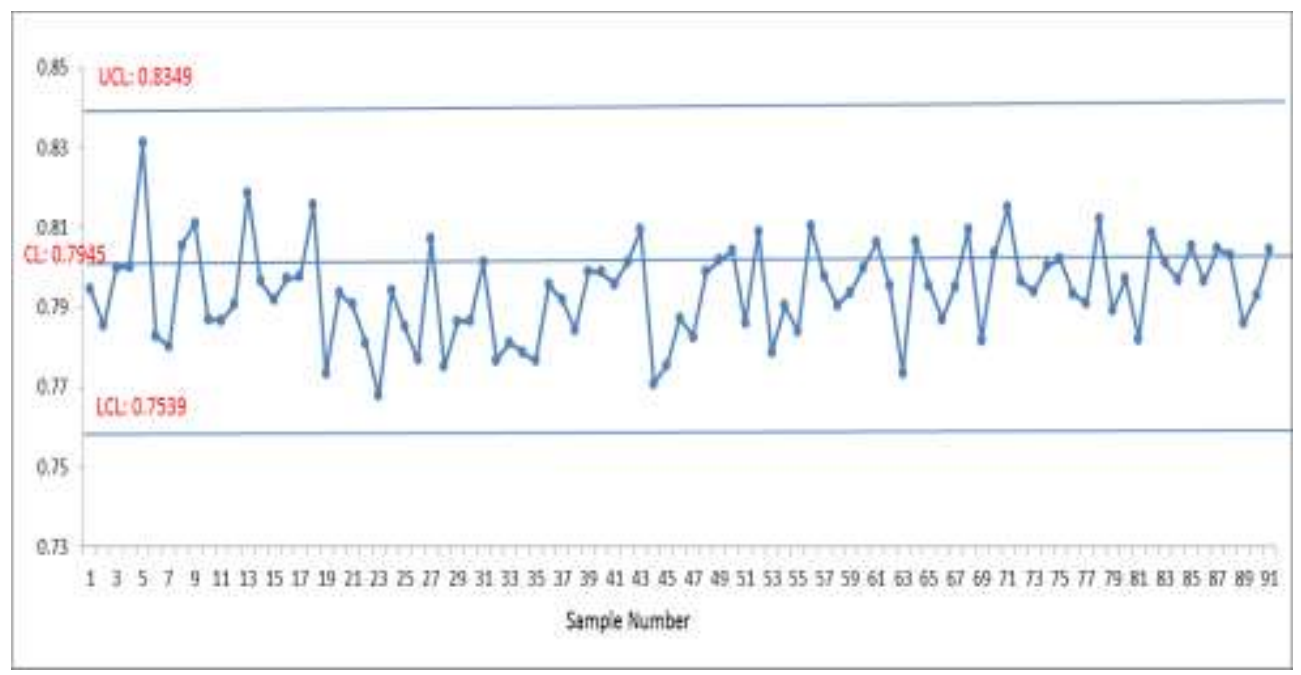

Figure 15: DS-Shewhart control chart for Real Data

The figure 15 shows the DS-Shewhart Control chart for the real life application. The UCL is calculated as $0.8349, \mathrm{CL}$ as 0.7945 and LCL as 0.7539 .

\subsection{DS-EWMA Control Chart}

The procedure defined in section 2.3 is used to evaluate the DS-EWMA control chart on the real data set of CSTR process. The control limits are calculated using $\gamma=0.1, L_{D S}=2.9$ :

Upper Control Limit $(\mathrm{UCL})=0.7945+2.9(0.0135)(0.23)=0.803505$

Center Line $(\mathrm{CL})=0.7945$

Lower Control Limit $(\mathrm{LCL})=0.7945-2.9(0.0135)(0.23)=0.785496$

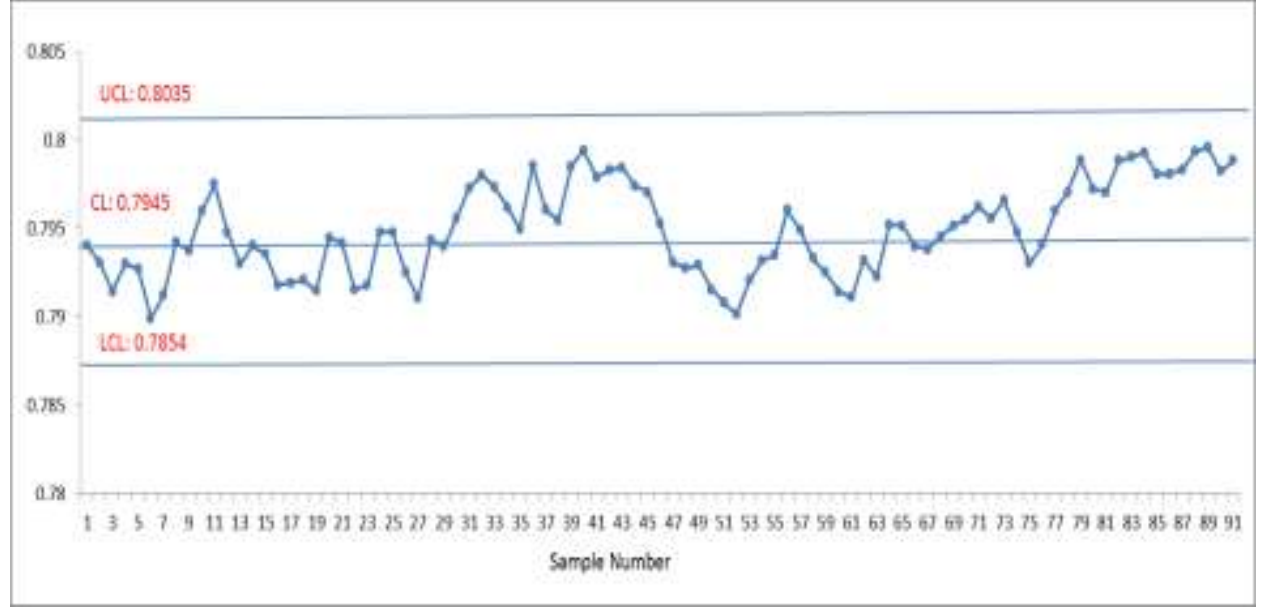

Figure 16: DS-EWMA control chart for Real Data 
The figure 16 shows the DS-EWMA Control chart for the real life application. The UCL is calculated as $0.8035, \mathrm{CL}$ as 0.7945 and LCL as 0.7854 .

\section{Conclusions}

In this paper, two new control charts have been proposed (i.e. DS-Shewhart control chart and DS-EWMA control chart). The proposed control charts are based on the exponential type estimator for mean proposed by Noor-ul-Amin and Hanif (2012). The results shows that the DS-Shewhart control chart shows more efficient results to traditional/simple Shewhart and EWMA control charts. The performance of the control charts is measured using average run length-out of control $\left(\mathrm{ARL}_{1}\right)$. The control chart showing less $\mathrm{ARL}_{1}$ will be awarded as more efficient chart as it will be more sensitive to the change and it will be detecting it more rapidly than other charts. It was observed that the ARL $L_{1}$ values for DS-Shewhart control chart is less than simple Shewhart and EWMA control charts, which shows DS-Shewhart control chart performs better than the simple Shewhart and EWMA control charts.

The DS-EWMA control chart also shows more efficient results to traditional Exponentially Weighted Moving Average (EWMA) and Cumulative Sum (CUSUM) control charts because they uses the information from two phase sampling with two auxiliary variables. The illustrative example based on simulation study is also conducted to compare the proposed and traditional/simple EWMA and CUSUM control charts performances based on the average run length-out of control $\left(\mathrm{ARL}_{1}\right)$. It is observed that the DS-EWMA control chart performs better than existing EWMA and CUSUM control chart. It is also observed that the DS-EWMA control chart out performs to DS-Shewhart in detection of outliers. A real life application for the proposed control charts is also given in last section. The proposed control charts can be used for efficient monitoring of the production process in manufacturing industries. The proposed methodology for construction of control chart using $t_{2}$ estimator can be used to developed control charting methodologies for other ratio, product and ratio cum product estimators in single and two phase sampling.

\section{Acknowledgements}

The author Syed Muhammad Muslim Raza is indebted to University of Management and Technology, Lahore, Pakistan for providing excellent research facilities.

\section{References}

1. Ahmad, S., Abbasi, S. A., Riaz, M., \& Abbas, N. (2014). On efficient use of auxiliary information for control charting in SPC. Computers \& Industrial Engineering, 67, 173-184.

2. Awan, W. H., \& Shabbir, J. (2014). On optimum regression estimator for population mean using two auxiliary variables in simple random sampling. Communications in Statistics-Simulation and Computation, 43(6), 1508-1522.

3. Aczel, A. D. (1989). Complete Business Statistics, Irwin. ISBN 0-256-05710-8.

4. Grant, E. L., Leavenworth, R. S. (1980). Statistical process control, 1980. 
5. Gupta, C. B., Gupta, V. (2009). Introduction to Statistical Methods, Vikas Publishing House Pvt Ltd.

6. Hanif, M., Hamad, N., \& Shahbaz, M. Q. (2009). A modified regression type estimator in survey sampling. World Applied Sciences Journal, 7(12), 1559-1561.

7. Kadilar, C., \& Cingi, H. (2006). An improvement in estimating the population mean by using the correlation coefficient. Hacettepe Journal of Mathematics and Statistics, 35(1).

8. Keller, G. (2015). Statistics for Management and Economics, Abbreviated. Cengage Learning.

9. Kotz, S. \& Johnson, N.L. (1988). Encyclopedia of statistical sciences. New York: Wiley.

10. Montgomery, D. C. (2007). Introduction to statistical quality control. John Wiley \& Sons.

11. Mandel BJ. (1969). The regression control chart. Journal of Quality Technology, $1,1-9$.

12. Noor-ul-Amin, M., Hanif, M. (2012). Some Exponential Estimators In Survey Sampling. Pakistan Journal of Statistics, 28(3), 367-374.

13. Rashid, N. A., Ghani, I. A., \& Mehad, S. (2010, June). Control charts based on regression adjustment. In Proceedings of the Regional Conference on Statistical Sciences (pp. 117-127).

14. Riaz, M. (2008). Monitoring process mean level using auxiliary information. Statistica Neerlandica, 62(4), 458-481.

15. Riaz, M. (2011). An improved control chart structure for process location parameter. Quality and Reliability Engineering International, 27(8), 1033-1041.

16. Riaz, M., \& Does, R. J. (2009). A process variability control chart. Computational statistics, 24(2), 345-368.

17. Singh, H. P., \& Vishwakarma, G. K. (2007). Modified exponential ratio and product estimators for finite population mean in double sampling. Austrian journal of statistics, 36(3), 217-225.

18. Singh, R., Kumar, M., \& Smarandache, F. (2008). Almost unbiased estimator for estimating population mean using known value of some population parameter (s). Pakistan Journal of Statistics and Operation Research, 4(2).

19. Wade, M. R., \& Woodall, W. H. (1993). A review and analysis of cause-selecting control charts. Journal of quality technology, 25(3), 161-169.

20. Woodall, W. H., Spitzner, D. J., Montgomery, D. C., \& Gupta, S. (2004). Using control charts to monitor process and product quality profiles. Journal of Quality Technology, 36(3), 309.

21. Watson, D. J. (1937). The estimation of leaf areas. Journal of Agricultural Science; 27:474.

22. Zhang, G. X. (1984). A new type of control charts and a theory of diagnosis with control charts. In World Quality Congress Transactions (Vol. 3, pp. 175-185). Milwaukee, WI: American Society for Quality Control. 